Research Article

\title{
Incidence and Prevalence of Coffee wilt Disease (Gibberella xylarioides) and Its Impact on the Rural Livelihoods in Western Guji Zone, Southern Ethiopia
}

\author{
Afrasa Mulatu*, Diriba Shanko \\ Department of Biology, College of Natural and Computational Sciences, Bule Hora University, Bule Hora, Ethiopia \\ Email address: \\ afrodan222@gmail.com (A. Mulatu) \\ ${ }^{*}$ Corresponding author
}

\section{To cite this article:}

Afrasa Mulatu, Diriba Shanko. Incidence and Prevalence of Coffee wilt Disease (Gibberella xylarioides) and Its Impact on the Rural Livelihoods in Western Guji Zone, Southern Ethiopia. American Journal of BioScience. Vol. 7, No. 1, 2019, pp. 7-15.

doi: $10.11648 /$ j.ajbio.20190701.12

Received: January 8, 2019; Accepted: February 13, 2019; Published: March 12, 2019

\begin{abstract}
The current research work was accompanied by the disease sample collection, isolation and identification of the causal agents involved in the coffee tree death complexes and evaluate the incidence and prevalence of coffee wilt disease (CWD) thereby evaluating the impact of the CWD on the livelihood of the coffee farmers in western Guji zone. The current status of CWD was systematically assessed and examined in 36 sample coffee farms across western Guji zone. At the same time, three to four samples of infected coffee tree parts were randomly collected from each plot and the causal pathogen was isolated and identified in the laboratory. Primary and secondary data sources were collected to determine the impact of CWD on rural livelihoods in the study area. The result indicated that CWD was prevalent in the study sites, with highest mean incidence of $53.1 \%$ in kercha, $49.1 \%$ in Hambela Wamana and $42.3 \%$ in Odo Shakiso districts that indicated the present status of the diseases is remarkably on increasing trend and poses a big threat to the farmers. The difference in incidence of CWD across the districts and among the peasant associations was strongly associated with human factors and variation in coffee production systems. In general, this research works implicated that CWD was developed to an important disease level and is one of the potential biotic factors affecting the livelihood of the rural people in the study area and thus the disease management practices should duly considered to tackle this devastating disease.
\end{abstract}

Keywords: Arabica Coffee, Biotic Factors, Coffee Production System, Pathogen, Districts

\section{Introduction}

Coffee is the most important agricultural commodity, worth an estimated retail value of 70 billion USD, crucial for the economy of more than 80 countries and the main income resource for hundreds of millions people worldwide. Next to petroleum, coffee (Coffea arabica L.) is the most widely traded commodity in the world, with an annual turnover exceeding US\$10 billion. Its production forms the backbone of more than 50 developing countries, with a contribution to the total foreign currency earnings reaching as much as $80 \%$ in the case of some African countries, such as Ethiopia [1, 2]. It is one of the most widely consumed beverages and represents a multibillion dollar global industry. It is also vital to the economy of East and Central Africa, providing a major source of foreign exchange earnings and, as a cash crop, supporting the livelihoods of millions involved in cultivation, processing, marketing and export [3].

Coffee has played an important role in the Ethiopian economy and represents the main cash crop cultivated by small scale farmers for social, economic, political and ecological sustainability [4]. Today Ethiopian coffee is part of a multi-billion dollar agribusiness of global significance. Coffee as a commodity has continued to play a leading role in the economy of Ethiopia. It has of immense national and global significance, being the country of origin of Arabica, the country that therefore holds the great majority of the Arabica 
gene pool, the first country to develop a coffee culture, and the country where the largest number of smallholders depend upon it for their livelihood; coffee is directly or indirectly a source of livelihood for more than about 25 million people engaged in production, processing, trading and marketing of the crop and it plays a fundamental role in both the cultural and socio-economic life of the nation [5]. It contributes about $5 \%$ of Ethiopia's Growth and Development Plan (GDP) and is the country's largest export item [6].

Coffee thus not only represents a large number people; the way it is grown and marketed encompasses aspects that are the very essence of current Ethiopian life. Coffee is at once and the same time rural and urban, modern and traditional, domestic and international, indigenous and foreign, public and private. Southern parts of the country; Guji, Gedeo and Sidamo zones, has a great potential of land for coffee cultivation. Despite the largest share in export and economic contribution, numerous constraints have been mentioned that affect the production and utilization of coffee. Of these constraints, coffee diseases are the most serious issue that calls for immediate control measures. The crop is prone to a number of diseases that attack fruits, leaves, stems and roots, and reduce the yield and quality of the produce [7]. Currently, coffee is under the threat of two kinds of diseases: co-evolved diseases, which have evolved with the host in its center of origin, such as coffee wilt disease (CWD), and new-encounter diseases, resulting from the adaptation of a native pathogen to an introduced crop, such as coffee berry disease (CBD) (only in Africa), and American Leaf Spot Disease (ALSD) (only in America). Pathogenic fungi in general and Fusarium species in particular are highly destructive pathogens of both greenhouse and field-grown major crops under favorable conditions [8].

Coffee wilt disease (CWD) is caused by Fusarium xylarioides Steyaert imperfect stage (Gibberella xylarioides Heim and Saccas Perfect stage). Coffee wilt disease results in a total death of the infected coffee trees. For centuries, Ethiopian coffee selections proved to be resistant or tolerant against many diseases and pests. Grown under indigenous shade trees coffee selections adopted to stand drought conditions and developed a certain tolerance. Coffee diseases are among the major biotic constraints of coffee in Ethiopia that attack fruits, leaves, stems and roots and thereby reduce the yield and marketability of the crop. Once a tree is infected, there is no remedy other than to uproot the tree and burn it in situ to reduce the chances of spreading the infection.

The prevalence of this disease and the assessment of the amount of yield loss due to CWD on the most grown variety of Coffee arabica $\mathrm{L}$. need higher consideration for the wellbeing of the community. The incidence of CWD in Ethiopia is reported to be $60 \%$ with significant yield losses due to severe damage and ultimate death of millions of coffee trees [9]. The scarcity of epidemiological information may partly account for the failure to control CWD using phytosanitary measures. Roguing and burning of affected trees is of some benefit but their adoption is constrained by on-farm resources.
A nationwide assessment study on CWD was conducted mostly on southern (Gedio and Sidama zones), eastern Hararge and southwestern parts of the country [4, 6, 10]. However, there was very little background information available and no documented records/publications on the current status of CWD distribution, severity and extent of damage and its impact on the rural livelihoods in western Guji zone. Thus, it is imperative to assess and update the distribution, extent of the damage caused by CWD and its impacts on the livelihood in coffee growing areas of Guji zone districts to obtain baseline information for the development of suitable interventions for the management of the diseases. A survey was conducted in the coffee growing regions of Guji zone districts that calls for strengthening disease management strategies with the aim to assess and evaluate the current status of CWD in the selected districts/districts of western Guji zone, to isolate and characterize G. xylarioides by using bioassay methods and to determine the impact of CWD on the rural livelihoods.

\section{Materials and Methods}

\subsection{Description of Study Areas}

The study was conducted on major coffee producing areas of Guji zone districts of southern Ethiopia. Coffee wilt disease (CWD) survey and assessment was conducted at four districts/districts, namely, Kercha, Odo Shakiso, Uraga and Hambela Wamena district coffee farms and gardens situated at middle and higher elevations in 2016/17 cropping season. The districts were chosen purposively because, it is among the districts to have been affected by the disease. It also contributes a large share of coffee produced in Ethiopia. Laboratory experiments were conducted in Mycology laboratory in the Department of Microbial, Cellular and Molecular Biology, Addis Ababa University (AAU), Ethiopia.

\subsection{Research Design}

A cross sectional research design was used given the nature of small coffee farmer settlements. This was combined with descriptive and analytical research designs based on the results from the questionnaires and interviews.

\subsection{Study Population}

The target population of the study was constituted of 60 coffee farmers in the selected districts ( 15 coffee farmers from each district). The agricultural extension officers and development agents in the area were also consulted along the study.

\subsection{Research Variables}

The independent variable was CWD, while the dependent variable were CWD incidence and its impact on rural livelihoods. 


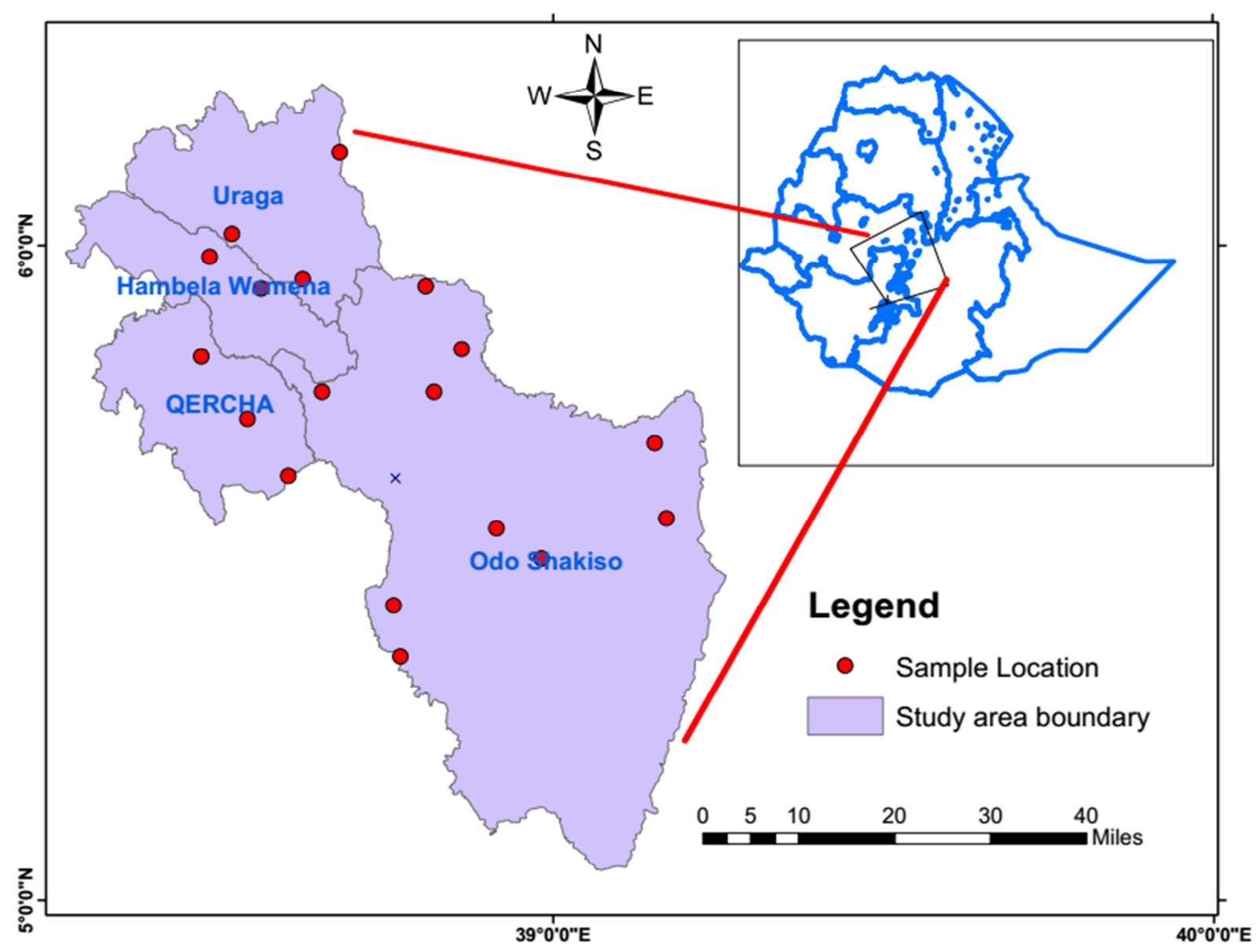

Figure 1. Description of geographical location of study areas.

\subsection{Sample Unit and Data Collection}

The assessment of CWD was conducted in 36 sampled coffee farms in 4 districts with potential of the country's coffee production and export. Two to five peasant associations (kebeles) per district and three coffee farms from each kebele were considered at every $15-20 \mathrm{~km}$ intervals for the study. The semi-structured questionnaires (translated to local languages) were used mainly to capture information on the physical environment, the production environment, the management system, flock structures, main uses, performance and phenotypic characteristics. Face to face (guided interviews) were used to flexibly repeat the questions to ensure that the respondents have got their meaning and information was obtained from those who cannot read and write. Altitude in meters above sea level (m.a.s.l) was taken, using a Garmin Ground Positioning System (GPS) at a central point for each farm surveyed. Data collected on incidence, severity and prevalence were summarized as means for all farms surveyed and standard errors were calculated.

\subsection{Isolation, Identification and Characterization of G. xylarioides}

In order to identify and confirm the causal agent, $G$. xylarioides, was collected from randomly selected coffee trees diseased leaves, stems (placed in kaki paper), and soils (placed in perforated polyethylene bags) of infected coffee trees showing partially wilting, completely wilted, dead, and apparently healthy symptom groups (two trees/symptom group) in each field. All samples were properly labelled with locations (district, field, coordinates and altitude) and collected date, brought to the Mycology laboratory at MCMB, AAU and refrigerated at $4^{\circ} \mathrm{C}$ until isolation took place. Cultural and morphological characteristics were used to identify and characterize the causal pathogen of CWD ( $G$. xylarioides) following the methods and procedures used by Adugna et al., Phiri and Baker, and Phiri et al. [4, 11, 12].

Serial dilution agar plating method was used to isolate $G$. xylarioides from the soil. Soil samples were serially diluted by adding $1 \mathrm{gm}$ of each soil sample into $9 \mathrm{ml}$ of sterile distilled water $\left(10^{-1}\right)$. The dilution process was continued until the dilution factors of $10^{-4}$. All dilutions are streaked on to Czapek Dox Agar (CDA) plates and incubated for 7 days at $25^{\circ} \mathrm{C}$. Dilution of $10^{-2}$ and $10^{-3}$ were purified by further streaking into agar plates until pure isolates were confirmed morphologically from grown colonies. The single colony was transferred to PDA in order to purify G. xylarioides. The fungus colony developing out of the plated section was purified on standard medium employing single spore isolation technique. The pure culture grown for 7-10 days under the same condition was identified as G. xylarioides based on the typical cultural and morphological characteristics of the 
fungus $[9,13]$. On the other hand, isolation from the stem specimens was accomplished following the techniques developed by Girma Adugna et al.[14] using recommended media (Synthetic Low Nutrient agar (SNA) for isolating and growing Fusarium species. The bark from the stem specimen was carefully removed and small sections $(0.5 \times 0.5 \mathrm{~cm})$ were excised from the intervening regions of discolored and white healthy wood using a sterile scalpel. All cultures were then incubated under $12 \mathrm{~h}$ fluorescent light and dark cycles at $22 \pm$ $2{ }^{\circ} \mathrm{C}$. The fungus colony grown out of plated section was purified and grown SNA and then on PSA to encourage development of pigmentation. After 10-14 days incubation under the same conditions, the fungus isolates were identified as $G$. xylarioides based on the typical cultural and morphological characteristics of the species.

\subsection{Coffee Wilt Disease Assessment Methods}

Coffee wilt disease (CWD) survey was conducted to assess the incidence and prevalence of the disease in the above mentioned districts in garden and semi-coffee production system during August and December 2016/17 cropping season. Three coffee fields/farms were selected in each kebeles (PAs) based on earlier surveys and preliminary information on the gained from agriculture development agents in the respective districts. CWD assessment was taken between plots across coffee farms. In each $100 \mathrm{~m} \mathrm{x} 100 \mathrm{~m}$ plot, 10-20 trees were diagnosed diagonally and consecutively following Girma Adugna and Hindorf [13] procedure. All diseased (dying and dead) coffee trees in each sample field were diagnosed. The progressive external symptom development along with internal discoloration on the wood, after peeling-off the bark, was observed and described. At the same time, the presence and/or absence of fungus fruiting body was examined visually or using a magnifying hand lens after gently scratching the bark.

Based on the external and internal symptoms, infected coffee trees by $G$. xylarioides were identified and recorded in the field. Then, the numbers of healthy and diseased trees counted and the incidence of CWD was computed as number of diseased trees/total number of observed coffee trees x 100 . The number of stumps and uprooted coffee trees were ascribed to wilting. Besides secondary information on cultivars, planting years (estimated age), cultural practices (slashing, hoeing, pruning etc.) and field history related to CWD and other related data were gathered during the surveys. CWD incidence was recorded based on the following scores: $1=$ absent/no symptom, $2=$ leaves curl inward, $3=$ dieback and defoliation (1-24\%), 4= dieback and defoliation (25-50\%), $5=$ dieback and defoliation $(51-75 \%)$ and $6=$ dieback and defoliation (76-100\%) [11].

\subsection{Statistical Data Processing and Analysis}

The data collected by the research instruments were edited, coded and reviewed for accuracy, consistence and completeness and entered into the computer using an appropriate package. Tables and charts were used in summarizing the data. Excel microcomputer statistical software was employed to design graphs for the assessment of CWD incidences and severity. The data were summarized on excel spreadsheet software and the mean incidence and prevalence were analyzed for each coffee farms. The data collected from the field through structured questionnaires were analyzed by employing the statistical procedures of SPSS version 24.0.

\section{Results}

\subsection{Coffee Wilt Disease Symptoms in the Field}

Affected coffee trees with G. xylarioides usually occur singly or in groups randomly in the characteristic symptoms of wilt disease. The early symptoms of infection on mature coffee trees are epinasty of leaves on some branches in the lower tree canopy that turn brownish within two or more weeks, and finally drop off from the branches. These external symptoms most frequently begin on one side of a coffee tree, and then gradually progress throughout the plant. Later in the season, completely wilted trees become dried barely with leafless branches and these trees cannot be easily pushed and uprooted. Internally, brown discolored bands are exhibited on the exposed wood of the stem. Brownish black fruiting bodies of the pathogen can be observed in barks of stems and branches of dead coffee. In the field, black to violet perithecia of the perfect stage are formed on or beneath the bark at the base of the stem.

The increase in the incidence was attributed on the environmental factors such as hot and humid weather conditions and a number of dead trees had been uprooted and burnt. Failure to weed, mulch and prune the coffee plantations were the main cause of CWD whereas sterilization and restricted movement of affected plant parts were control methods in addition to uprooting and burning which were labour intensive.

\subsection{Cultural Characteristics of Gibberella xylarioides}

Six G. xylarioides were isolated from the infected leaf and stem of coffee plants. The wood samples of the most of the infected coffee trees $(86.7 \%)$ yielded $G$. xylarioides in the laboratory proving that this pathogen is the main cause of coffee tree death in the study areas. Isolates Gx.1 and Gx.2 of Gxylarioides showed relatively slow growth less than $7 \mathrm{~cm}$ on PDA after 10 days of incubation with light purple color and did not show aerial mycelium. The color of the colony was white to light purple diffusing into agar (Gx.3 and Gx.4). Gx.5 isolate of $G$. xylarioides showed relatively slow growth, less than $7 \mathrm{~cm}$ in diameter after 10 to 14 days of incubation. The color of aerial mycelium of Gx.5 was white, tan to carmine red according to age, and when observed from below, light purple color may diffuse into agar. 


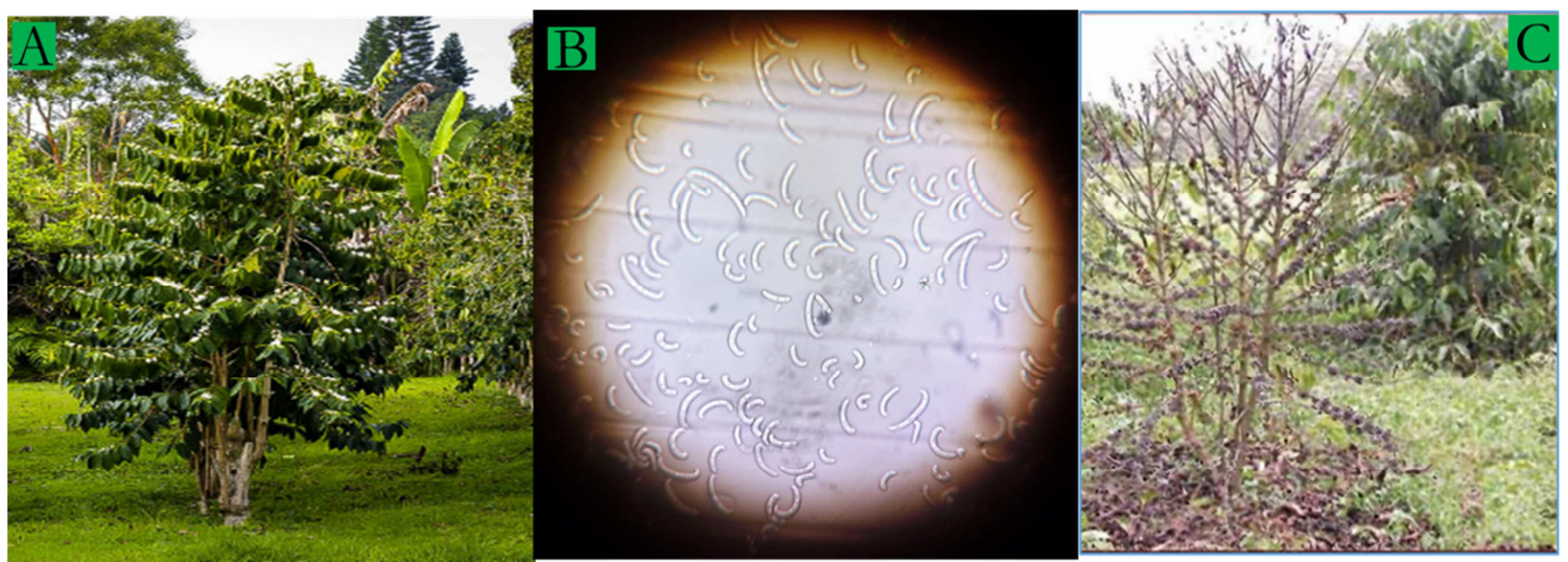

Figure 2. Symptoms of CWD on Arabica coffee tree: (A) Healthy Coffee tree, (B) Gibberella xylarioides conidia, (C) Typical dead coffee tree.

\subsection{Microscopic Appearances of Gibberella xylarioides}

Sporodochoia were observed in all of the six isolates. The spores appeared in the form of small slimy clusters of microconidia at the apex of short, cylindrical conidiogeneous cells on the vegetative mycelium. Microconidia were abundant and strongly curved or in the form of colorless slimy droplets at the apex of elongated conidiogeneous cells. The mean conidial dimensions of the isolates were $21 \times 3.03 \mu \mathrm{m}$ in macroconidia and from $8.75 \times 2.35 \mu \mathrm{m}$ in microconidia. $G$. xylarioides produces macroconidia and microcondia which were variable in shape and size with 1 to 3 septate. The macroconidia were cylindrical, slightly curved and curved with hooked ends while the microconidia were frequently allantoid and U-shaped with or without a septum. The average macroconidia size ranged from $11.5 \times 30.5$ to $2.3 \times 3.75 \mu \mathrm{m}$, while that of microcondia varied between $5.0 \times 12.5$ and $2.0 \times$ $2.7 \mu \mathrm{m}$ (Table 1).

Table 1. Average length and width of conidia $(\mu \mathrm{m})$ of six isolates of G. xylarioides, after 12 days of growth on PDA.

\begin{tabular}{lllll}
\hline \multirow{2}{*}{ Isolate } & \multicolumn{2}{l}{ Macroconidia } & Microconidia & Width \\
\cline { 2 - 5 } & Length & Width & Length & $2.0-2.5$ \\
\hline Gx.1 & $15.0-30.5$ & $3.0-3.25$ & $5.0-10.0$ & $2.0-2.5$ \\
Gx.2 & $17.5-27.5$ & $3.0-3.5$ & $5.0-7.5$ & $2.25-2.5$ \\
Gx.3 & $11.5-25.0$ & $2.75-3.75$ & $5.0-10.5$ & $2.0-2.5$ \\
Gx.4 & $20.0-25.0$ & $2.70-3.50$ & $7.5-12.5$ & $2.5-2.7$ \\
Gx.5 & $15.0-17.5$ & $2.70-3.25$ & $7.50-10.0$ & $2.4-2.6$ \\
Gx.6 & $16.3-19.8$ & $2.3 .-3.6$ & $7.3-9.68$ & $2.0-2.7$ \\
Range & $11.5-30.5$ & $2.3-3.75$ & $5.0-12.5$ & 2.35 \\
Mean & 21 & 3.03 & 8.75 & \\
\hline
\end{tabular}

Legend: $\mathrm{G} . \mathrm{x}=$ Gibberella xylarioides

\subsection{Occurrence and Distribution of CWD in Coffee Production System}

Coffee wilt disease was prevalent in all assessed coffee producing districts of western Guji zone. The result indicated that CWD was prevalent in the study sites, with highest mean incidence of $53.1 \%$ in kercha, $49.1 \%$ in Hambela Wamana and $42.3 \%$ in Odo Shakiso districts that indicated the present status of the diseases is remarkably on increasing trend and poses a big threat to the farmers. On the other hand, the lowest disease incidence $(25.4 \%)$ was estimated Uraga district (Figure 2). The magnitude and extent of damage caused by the disease varied significantly $(\mathrm{p}<0.001)$ among districts and peasant associations. The difference in incidence of CWD across the districts was strongly associated with human factors and variation in coffee production systems. CWD was highly prevalent and severe in garden coffee production systems in the surveyed districts. In general, this research works implicated that CWD was developed to an important disease level and is one of the potential biotic factors affecting the livelihood of the rural people in the study area and thus the disease management practices should duly considered to tackle this devastating disease. The wood samples of the most of the infected coffee trees $(86.7 \%)$ yielded G. xylarioides in the laboratory proving that this pathogen is the main cause of coffee tree death in the study areas. 


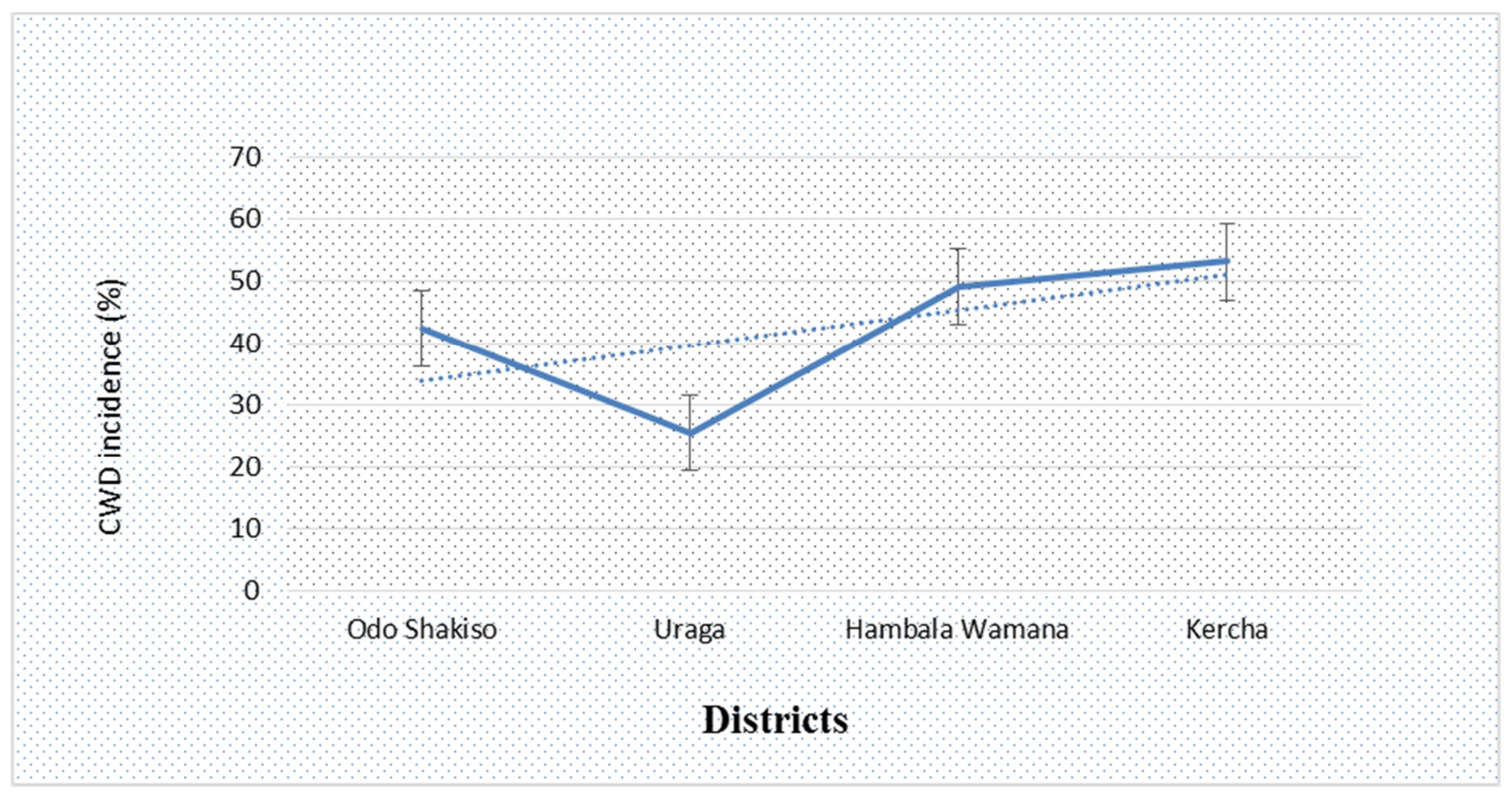

Figure 3. Incidence of CWD of Western Guji zone.

Unlike with other coffee diseases, namely, CBD and CLR, coffee trees infected by CWD cannot be saved. Successful control of the disease depends on the principles of disease prevention (avoid wounding of any part of the plant) and phyto-sanitation. The conventional phytosanitary approach of uprooting and burning the whole infected coffee tree on the spot is strongly recommended to coffee farmers to contain the disease as soon as symptoms are seen, but this relies on early diagnosis.

Table 2. Incidence of CWD in Western Guji zone districts in 2016/17 cropping season.

\begin{tabular}{llll}
\hline \multirow{2}{*}{ District/districts } & $\begin{array}{l}\text { Altitude Range } \\
\text { (m.a.s.l) }\end{array}$ & CWD incidence (\%) & \\
\cline { 3 - 4 } & $1685-1749$ & Range & Mean and SD \\
\hline Odo Shakiso & $1892-1925$ & $37.0-47.5$ & $42.25 \pm 7.5$ \\
Uraga & $2195-2218$ & $22.6-28.2$ & $25.4 \pm 4.0$ \\
Hamballa Wamana & $2014-2137$ & $38.0-65.6$ & $49.1 \pm 18.2$ \\
Kercha & $21.7-67.2$ & $53.1 \pm 18.2$ \\
\hline
\end{tabular}

\subsection{Influence of Agronomic Practices on CWD Incidence}

The surveyed farms were well managed and weed free, but all other management practices were very traditional indicating lack or inadequate extension services particularly in training the farmers on appropriate coffee management practices. The farmers have no any awareness about pruning (multiple or single stem), handling (sucker control, removal of dense, intermingled and dead branches, etc.) and control of number of verticals or main stems per individual tree. Coffee tree management is generally free growth and an individual tree can have as many verticals (main stems) as it can naturally bear, a typical traditional practice. Lack of proper pruning affect bean size and quality, reduce yield, increase proportion of floater beans, encourage pest (diseases and insect pests) development and consequently reduce the final income of the farmers from coffee.

In the study area, coffee was mainly grown as an intercropping system with different crops like sorghum, maize, haricot bean, fruit trees and banana were very widespread agricultural practices. Fruit trees and false banana were commonly planted at random on coffee farms, providing a heterogeneous shading pattern for coffee trees growing underneath. The survey findings revealed that farmers were grown different coffee landraces which are low yielder and poor in their resistance toward disease, pests and drought problems. According to farmers the productivity of coffee decreased from time to time, due to lack of improved varieties in the study area.

\subsection{Demographic Characteristics of the Respondents}

\subsubsection{Gender and Marital Statistics}

Study findings show that majority of the respondents were females accounting for $55 \%$ as compared to the males with $45 \%$. The majority of the respondents were married (65\%). Of those, $70 \%$ had children. Others were still single and divorced among other categories. Other variables of interest included age and education, as explained below.

\subsubsection{Age Statistics of the Respondents}

Statistics collected indicated that the majority of the interviewees were aged 31 years and above (Table 3 ). 
Table 3. Age statistics.

\begin{tabular}{lll}
\hline Age bracket & Frequency & Percentage (\%) \\
\hline $20-30$ & 11 & 18.3 \\
$31-40$ & 23 & 38.3 \\
$41-50$ & 24 & 40 \\
50 years and above & 2 & 3.3 \\
Total & 60 & 99.9 \\
\hline
\end{tabular}

Results in table 3 , show that majority of the respondents were aged between $31-50$ years, accounting for $68.3 \%$, while 20-30 years and 50 years and above had $18.3 \%$ and $3.3 \%$ respectively.

\subsubsection{Education and Occupation of the Respondents}

The education level data indicate that most of the households held certificates, diplomas and degrees (52\%), while the others interviewed held no certificate (48\%). The chief occupation of the respondents was farming.

\subsubsection{The Role Played by Coffee on Rural Livelihoods}

Primary sources was used and data was collected using both interviews and questionnaires to determine the impact of CWD on rural livelihoods in the study area. Secondary data sources were also used to supplement the data that was collected from the primary sources. The study confirmed that coffee farming is very vital on rural livelihoods in the study area as it forms the basis of income for the majority. The majority of the respondents $(90 \%)$ accepted that coffee farming has transformed their lives, while only $10 \%$ disagreed.

\section{Discussion}

During the period of assessments of the disease in 2016/17 cropping season, CWD was detected in all the indigenous coffee field sites. The wilting symptom most frequently starts in branches on one side of infected tree that gradually progresses throughout the plant and finally become dried and stand barely with leafless branches. The external and internal coffee wilt disease symptoms are similar to those previously described by Adugna et al. [4, 9] on Arabica coffee. The pathogen exists on coffee trees in two developing stages: Gibberella as the sexual or perfect stage producing wind-borne ascospores and Fusarium as the asexual or imperfect stage with splash-borne conidia. Infection mostly takes place at the imperfect stage penetrating through wounds into the base of the stem. The fungus blocks the water supply in the vascular system and causes a typical brown discoloration $[2,12,15]$.

All G. xylarioides isolates were slow grower and on PDA after 10 days of incubation it attained full growth at $25^{\circ} \mathrm{C}$. In line with this findings, the cultures of $G$. xylarioides isolates have invariably shown typical growth, color and pigment descriptions of anamorph state G. xylarioides [16]. Based on the aerial mycelia growth, the isolates were grouped as appressed (flat)-sparse, slightly raised-slightly dense (intermediate) and raised and dense texture. At district level, the disease incidence ranged between $21.7-67.2 \%$ in Kercha and $38-65.6 \%$ in Hambela Wamena. Higher mean CWD incidence was recorded in Kercha (53.1\%) and Hambela Wamena (49.1\%); both districts are known to have susceptible coffee in the garden production system, which was not significantly different from Odo Shakiso (42.3\%).

G. xylarioides was a troublesome soil borne disease of Arabica coffee (Coffea arabica L.) in southern parts of Ethiopia. A number of recent reports have also indicated that the disease is equally damaging coffee trees with varying intensities thereby endangering the conservation of wild coffee genetic resources in forest coffee systems of the country. In this case also, the Harenna isolates differed from the others with slightly raised and slightly dense (66.7\%) and flat-sparse $(33.3 \%)$ colony as opposed to Bonga, Berhane-Kontir and Yayu populations that showed intermediate growth type slightly raised-dense (80\%) and $20 \%$ was appressed (flat) and sparse. The radial growth rate analysis showed that the Harenna isolates grow faster than those isolates from southwest coffee areas including Gera and Jimma during the first 10 days of incubation; although, they became slower than the other groups as colonies got older. Berhane-Kontir isolates exhibited the reverse growth pattern. Similar to the present study, Adugna [9] reported varying radial growth rate among $G$. xylarioides populations collected from different coffee types and geographic localities in Africa. Among the $G$. xylarioides isolates, those from the southern region relatively grow at slower rates $(3.1 \mathrm{~mm} /$ day $)$ than those isolates collected in southwestern $(4.0 \mathrm{~mm} /$ day $)$ Ethiopia. In general, the cultural characteristics of Gibberella isolates ranged from very sparse and appressed to dense and raised colony with grayish, light bluish and purplish or violate pigments which were orange, flat and pionnotal in appearance. G. xylarioides produces macroconidia and microcondia which were variable in shape and size with 1 to 3 septate. The findings on the cultural and morphological characteristics of this fungus were in agreement with the reports of previous work on large number of strains collected from Arabica and Robusta coffee [9, 16, 17].

Coffee wilt disease was prevalent in all assessed coffee producing zones of southern Ethiopia with different magnitude and extent of damage among districts, peasant associations and zones. Higher mean CWD incidence was recorded in Kercha (53.1\%) Wonago (52.3\%); both zones are known to have susceptible coffee in the garden production system, which was not significantly different from Hambela Wamena (49.1\%). The results of this study are in line with the already documented findings on the coffee wilt pathosystem Adugna [4], Adugna et al., [14] and Adugna and Hindorf, [13] that support the occurrence of predominantly horizontal resistance with few vertical type of reactions in the wild Arabica coffee populations. CWD was more prevalent in fields of garden production system like Harar and Bale area with severity range of between $27.2 \%$ and $43.5 \%$ which is high compared to that of the semi-forest coffee production system Adugna [4]. The incidence of CWD was above 35\% in garden coffee of West Gojam zone of Amhara regional state [6]. Hindorf and Omondi [18] technical report indicated that 
the national incidence and severity of CWD in Ethiopia were $27.9 \%$ and $3 \%$, in monitory terms it causes an estimate loss of more than 3.7 million USD annually, respectively. However, the incidence and severity varied from place to place in a range of $0-100 \%$ and $0-25 \%$, respectively [11].

Recently, Getachew et al. [19] reported that coffee wilt is causing significant losses to coffee trees in the forest coffee systems of Ethiopia inhabiting invaluable gene pools of $C$. arabica $\mathrm{L}$. The highest mean incidence was about $29.2 \%$ in Harenna forest coffee (southeast), followed by Berhane-Kontir (southwest) with mean incidences that varied from 22 to $28 \%$ during 2008 and 2009 seasons. The overall comparison of coffee wilt progress over the years indicated that the disease pressure has been increasing in the forest, semi forest and garden coffee across all sites. The severity of wilting in the sample fields in Yirga cheffe varied between $27.2 \%$ and $43.5 \%$ in the garden coffee as compared to that of the semi-forest coffee [18]. Although the disease was not evenly distributed in most coffee-growing areas of SNNP region, the average incidence (35\%) and severity $(5.0 \%)$ was significantly $(\mathrm{P}<0.001)$ higher than in other regions. It was particularly high in the Sidama and Gedeo zones, with an incidence over $90 \%$ and severity of $25 \%$. Use of CWD-infected trees for any purpose is prohibited, and replanting with susceptible coffee seedlings should be delayed at least for 2 years to avoid the distribution of the pathogen among coffee farms $[4,6,20]$.

The management practices were very traditional that indicated the lack or inadequate extension services particularly in training the farmers on appropriate coffee wilt disease management practices in the surveyed districts. The increase in intensity of CWD in this study report conceivably emanated from the extensive planting of susceptible local coffee landraces aggravated by non-application of fungicides to control the disease over the past two decades. In line with this, some of the released good yielding and moderately resistant cultivar were gradually became susceptible after planting by many growers in southern Ethiopia [21] that might contribute to rise in CWD incidence in southern parts of Ethiopia.

Therefore, coffee management systems based strategies that enhances coffee's resilience to perturbations and exhibits natural strengths against future risks should be applied. An adequate system should be able to provide timely information to coffee farmers and authorities about the risk of CWD and propose appropriate actions to prevent productivity and social crises. In any case, whichever technical solution is implemented for the control of CWD, it will need the participation of experienced farmers, farmers'/peasant associations and extension services working in conjunction for the measures to be effective. Strengthening of linkages between the actors involved in the supply and marketing chain, national and international technical and research organizations and funding agencies are very crucial. All these partners have key roles to play in strengthening the rural communities and improving smallholder livelihoods.

\section{Conclusion}

In conclusion, this survey along with the earlier works implicated that CWD was developed to an important disease level and prevalent with significantly $(p<0.001)$ varied intensity of damage among fields and districts of western Guji zone. The highest mean CWD incidence was recorded in kercha $(53.1 \%)$ district that indicates the present status of the disease is remarkably on increasing trend. These empirical evidences shows that CWD was on an upsurge and remains a major challenge to Arabica coffee production in the study area The study confirmed that coffee farming is very vital on rural livelihoods in the study area as it forms the basis of income for the majority of the population.

\section{Acknowledgements}

The authors wish to express their sincere thanks and appreciation to Bule Hora University for providing financial support and Addis Ababa University, Department of Microbial Cellular and Molecular Biology is acknowledged for their research facilities they provided being allowing us to conduct the laboratory experiments in Mycology laboratory.

\section{References}

[1] Flood, J., 2010. The importance of plant health to food security. Food Secur., 2 (3): 215-31.

[2] Phiri and Baker, 2009. Coffee wilt disease in Africa; a synthesis of the work for the Regional Coffee Wilt Programme (RCWP). In, (Ed.)^(Eds.). Final Technical Report. CABI: pp.

[3] Girma Adugna, A. Million, H. Hindorf, Arega Zeru, D. Teferi, and Chala Jefuka, 2010. 4 Coffee Wilt Disease in Ethiopia. Coffee Wilt Disease: 50.

[4] Adugna, G., M. Adana, H. Hindorf, A. Zeru, D. Teferi, and C. Jefuka, 2010. Coffee Wilt Disease in Ethiopia. 50.

[5] Girma Adugna, Chala Jefuka, Demelash Teferei, and Arega Zeru, 2008. Multiple resistances to Coffee Berry Disease, Coffee Wilt and Leaf Rust in Coffea arabica populations of Ethiopia. XXII ASIC, Campinas, SP, Brazil.

[6] Alemu, T., 2012. A review of coffee wilt disease, Gibberella xylarioides (Fusarium xylarioides) in Africa with special reference to Ethiopia. Ethiop. J. Biol. Sci., 11 (1).

[7] Derso, E., 2000. Preselection Methods for Coffee Berry Disease (CBD) Resistance in Ethiopia.

[8] McDougall, G. J., N. N. Kulkarni, and D. Stewart, 2008. Current developments on the inhibitory effects of berry polyphenols on digestive enzymes. BioFactors, 34 (1): 73-80.

[9] Adugna, G., 2004. Diversity in pathogenicity and genetics of Gibberella xylarioides (Fusarium xylarioides) populations and resistance of Coffee species. Ethiopia. PhD dissertation. University of Bonn, Bonn, Germany.

[10] Adugna, G., B. Balachew, S. Tesfaye, T. Endale, and T. Kufa, Year. Group discussions, synthesis and recommendations. Coffee diversity and knowledge. In: (Ed.) $)^{\wedge}$ Eds.), 505-10: 505-10. 
[11] Phiri, N. and P. Baker, 2009. A synthesis of the work of the Regional Coffee Wilt Programme 2000-2007.

[12] Phiri, N., M. Kimani, E. Negussie, S. Simons, and G. Oduor, 2010. Management of Coffee Wilt Disease. Coffee Wilt Disease: 137.

[13] Adugna, G. and H. Hindorf, Year. Recent investigation on coffee Tracheomycosis, Gibberella xylarioides (Fusarium xylarioides) in Ethiopia. In: (Ed.)^(Eds.), 165-71: 165-71.

[14] Adugna, G., C. Chufuka, D. Teferi, and A. Zeru, Year. Multiple resistances to coffee berry disease, coffee wilt and leaf rust in Coffea arabica populations. In: (Ed. $)^{\wedge}($ Eds. $)$ Association Scientifique Internationale du Café (ASIC), 1454-62: 1454-62.

[15] Pieters, R. and N. Van der Graaff, 1980. Resistance to Gibberella xylarioides in Coffea arabica: evaluation of screening methods and evidence for the horizontal nature of the resistance. Nether. J. Plant Pathol., 86 (1): 37-43.

[16] Rutherford, M., D. Bieysse, P. Lepoint, and H. Maraite, 2009. Biology, taxonomy and epidemiology of the coffee wilt pathogen Gibberella xylarioides sensu lato. Coffee Wilt Disease: 99-119.
[17] Rutherford, M. A., 2006. Current knowledge of coffee wilt disease, a major constraint to coffee production in Africa. Phytopathol., 96(6): 663-66.

[18] Hindorf, H. and C. O. Omondi, 2011. A review of three major fungal diseases of Coffea arabica L. in the rainforests of Ethiopia and progress in breeding for resistance in Kenya. J. Advanced Res., 2 (2): 109-20.

[19] Getachew, S., G. Adugna, F. Lemessa, and H. Hindorf, 2012. Coffee wilt disease (Gibberella xylarioides Heim and Saccas) in forest coffee systems of southwest and southeast Ethiopia. Plant Pathol. J.

[20] Arega Zeru, Fassil Assefa, Girma Adugna, and H. Hindorf, 2012. Occurrence of fungal diseases of Coffea arabica L. in Montane Rainforests of Ethiopia. J. Appl. Bot. Food Qual., 82 (2): $148-51$.

[21] Teferi, D. and K. Belachew, 2015. Evaluation of released arabica coffee varieties (Coffea arabica L.) for major coffee diseases with especial emphasis to coffee wilt disease (Gibberella xylarioides) at Jimma, Ethiopia. Evaluation, 5 (15). 